\title{
Adsorption of lead, ethylenediaminetetraacetic acid and lead- ethylenediaminetetraacetic acid complex onto granular activated carbon
}

\author{
*M. S. Vohra \\ Environmental Engineering Program, Civil Engineering Department, King Fahd University of Petroleum and \\ Minerals, Dhahran 31261, Kingdom of Saudi Arabia
}

Received 13 September 2009; revised 22 May 2010; accepted 2 July 2010; available online 1 September 2010

\begin{abstract}
This study investigated simultaneous removal of lead and ethylenediaminetetraacetic acid from synthetic wastewater samples using granular activated carbon adsorption. Data from a $1 \times 10^{-4} \mathrm{M}$ lead-ethylenediaminetetraacetic acid adsorption isotherm study fitted well to Freundlich isotherm. Furthermore, for the pH-dependent $1 \times 10^{-4} \mathrm{M}$ leadethylenediaminetetraacetic acid study both lead and ethylenediaminetetraacetic acid adsorptions increased reaching values of $82 \%$ and $93 \%$ respectively at $\mathrm{pH} 5.8$. However, a further increase in $\mathrm{pH}$ resulted in decreasing but near equal lead and ethylenediaminetetraacetic acid removals. Results for the $2 \times 10^{-4} \mathrm{M}$ lead-ethylenediaminetetraacetic acid system showed a behavior that was qualitatively similar to the $1 \times 10^{-4} \mathrm{M}$ lead-ethylenediaminetetraacetic acid findings. However, the $1 \times 10^{-3} \mathrm{M}$ lead-ethylenediaminetetraacetic acid study showed only a decreasing adsorption trend. An increasing-decreasing type lead/ethylenediaminetetraacetic acid adsorption behavior was also noted for the $1 \times 10^{-4} \mathrm{M} \mathrm{lead} / 2 \times 10^{-4} \mathrm{M}$ ethylenediaminetetraacetic acid system. Nevertheless for the $2 \times 10^{-4} \mathrm{M}$ lead $/ 1 \times 10^{-4} \mathrm{M}$ ethylenediaminetetraacetic acid system, lead removal at increased $\mathrm{pH}$ was comparatively higher. Furthermore, results from a continuous column study completed at $1 \times 10^{-4} \mathrm{M}$ lead and $0.75 \times 10^{-4} \mathrm{M}$ ethylenediaminetetraacetic acid showed high saturation times both for lead and ethylenediaminetetraacetic acid. Results from the present work show that a notable removal of aqueous phase lead and ethylenediaminetetraacetic acid could be achieved using activated carbon adsorption. The details related to the effect of $\mathrm{pH}$ and pollutants' concentration on the overall adsorption efficiency, as reported in the present work, would be of much use for an effective carbon adsorption process design for the treatment of respective wastewaters.
\end{abstract}

Keyw ord: Activated carbon; Adsorption; Ethylenediaminetetraacetic acid; Lead

\section{INTRODUCTION}

Presence of heavy metals such as lead and other pollutants in industrial wastewater from sources such as smelting, electroplating, metal finishing, metallurgy, chemical manufacturing, lead-batteries recycling, etc., remains a matter of serious concern because of related health issues (Palacios et al., 2002; Abdel-Ghani and Elchaghaby, 2007; Abdel-Ghani et al., 2009; Gaur and Dhankhar, 2009; Igbinosa and Okoh, 2009; Malakootian et al., 2009; Shah et al., 2009; Zvinowanda et al., 2009). Additionally presence of extensively used chelating agent ethylenediaminet etraacetic acid (EDTA) in varying aqueous environments and its subsequent effect onto increased metal species bioavailability including lead, is gaining attention as well (Swanson, 1984, 1985; Riley et al., 1992; Vohra and Davis, 1998;

凶*Corresponding Author Email: vohra@kfupm.edu.sa Tel.: +966038602854; Fax: +966038602879
Bargar et al., 1999; Kim and Ong, 1999; Palacios et al., 2002; Oviedo and Rodríguez, 2003; Xia et al., 2009). Though free aqueous phase lead species can be conveniently removed using traditional techniques such as metal precipitation, however, the presence of EDTA renders such processes either partially or completely ineffective because of a strong metal-chelate complex formation (i.e., lead-EDTA). Considering this, several approaches have been proposed to remove lead that is complexed to EDTA including use of anion exchange resins (Dudzinska and Clifford, 1991,1992; Kołodińska et al., 2009), cation-exchange membrane (Juang et al., 1999), integrated cation-exchange membrane with electrokinetic extraction (Amrate et al., 2006), a specific chemical process that includes EDTA recycling (Kim and Ong, 1999; Gaur and Dhamkhar, 2009) and advanced oxidation (Jiraroj et al., 2006; Vohra and Davis, 2000). 
Furthermore, though several investigations do report lead removal using different carbon based adsorption materials, including the traditional activated carbon (Taylor and Kuennen, 1994; Zhang et al., 2005; Issabayeva et al., 2006; Giraldo and Moreno-Piraján, 2008; Aghamohammadi et al., 2007), activated carbon cloths (Kadirvelu et al., 2000; Faur-Brasquet et al., 2002), carbon aerogel (Goel et al., 2005) and carbon nanotubes (Li et al., 2005) but studies reporting activated carbon initiated removal of lead in the presence of EDTA are few (Abdulkarim and Abu Al-Rub, 2004; Awwad et al., 2008; Krishnan et al., 2003; Reed and Arunachalam, 1994; Reed et al., 1994). Furthermore, most of these lead/EDTA activated carbon adsorption studies have focused only on lead removal with no detailed mention of EDTA's fate. For example, Abdulkarim and Abu Al-Rub, (2004) reported significant decrease in lead uptake by activated carbon in the presence of EDTA. Similarly, Reed and Arunachalam (1994) found that the amount of aqueous phase lead that was not adsorb was comparable to its complexed form (i.e., lead-EDTA) whereas Reed et al. (1994) noted that metal complexed to EDTA was not adsorbed on to activated carbon from the aqueous waste streams. Krishnan et al. (2003) report that lead adsorption in the presence of chelating agent was enhanced in $\mathrm{pH}$ range 2-5 but reduced in $\mathrm{pH}$ range 6-8. However a detailed study exploring the effect of both lead and EDTA on each other's adsorption on to activated carbon, at different stoichiometric ratios and $\mathrm{pH}$ values, has not been investigated to the best of found knowledge. Nevertheless a better understanding of such a simultaneous adsorption behavior is indeed needed to design effective granular activated carbon (GAC) systems for the treatment of respective waste streams. Hence the present study's main objective was to investigate the simultaneous adsorption behavior of both lead and EDTA on to GAC under varying mixed conditions. The obtained findings will be helpful to design efficient GAC systems for the removal both lead and EDTA species from respective co-polluted aqueous streams. All research work was performed in the Laboratory of Civil Engineering Department, King Fahd University of Petroleum and Minerals, during 2008 and 2009.

\section{MATERIALS AND METHODS}

All chemicals used for the present study were of high purity reagent grade quality. The major chemicals included $\mathrm{Pb}\left(\mathrm{NO}_{3}\right)_{2}[\mathrm{BDH}], \mathrm{Na}_{2} \mathrm{C}_{10} \mathrm{H}_{14} \mathrm{O}_{8} \mathrm{~N}_{2} \cdot 2 \mathrm{H}_{2} \mathrm{O}$ or $\mathrm{Na}_{2}$ EDTA [Fisher], FiltraSorb 400 granular activated carbon or GAC [FiltraSorb F400], $\mathrm{HClO}_{4}$ [BAKER], $\mathrm{NaOH}$ [FISHER] and $\mathrm{pH}$ calibration standards [FISHER]. For the $1 \times 10^{-4} \mathrm{M}$ lead-EDTA adsorption isotherm experiment, a set of ten clean glass bottles was first arranged and $100 \mathrm{~mL}$ of respective synthetic wastewater sample was then transferred into each bottle. The respective synthetic wastewater samples for this and all other adsorption experiments as reported in this work were prepared using high purity water (CORNING mega pure $^{\mathrm{TM}}$ system) and stock solutions of respective chemicals. After this GAC quantities between 0.1 to $10.0 \mathrm{~g} / \mathrm{L}$ were transferred to the individual glass bottles. A blank sample bottle without GAC was also always included to account for any pollutant loss because of reasons other than adsorption. The respective bottles were then appropriately sealed and transferred to the shaker. Samples for pollutant analysis were then collected at appropriate time intervals, till the adsorption equilibrium was noted, i.e., the $3^{\text {rd }}$ day. The respective data, i.e., pollutant concentration remaining at equilibrium Vs amount of GAC, was recorded and then subjected to further analysis. As respective results showed near-complete EDTA removal at GAC amount $\geq 2 \mathrm{~g} / \mathrm{L}$ at $3^{\text {rd }}$ day, a lower GAC amount i.e., $1 \mathrm{~g} / \mathrm{L}$ was subsequently used for all other experiments to avoid the masking effect resulting from high GAC amount and thus correctly quantifying the pollutant amountadsorbed. The $1 \times 10^{-4} \mathrm{M}$ Pb-EDTA adsorption equilibrium data was fitted both to the Langmuir and Freundlich adsorption isotherms. However, the Freundlich adsorption isotherm comparatively provided a better fit both for lead and EDTA adsorption data. The Freundlich adsorption model is represented as:

$\mathrm{q}_{\mathrm{e}}=[\mathrm{X} / \mathrm{M}]=\left[\mathrm{k}\left(\mathrm{C}_{\mathrm{e}}{ }^{1 / \mathrm{n}}\right)\right]$

Where,

$\mathrm{X}=$ Amount of pollutant adsorbed at equilibrium $=\mathrm{C}_{\mathrm{o}}$ $-\mathrm{C}_{\mathrm{e}}(\mathrm{mg} / \mathrm{L})$

$\mathrm{C}_{\mathrm{o}}=$ Pollutant's initial concentration at time zero $(\mathrm{mg} / \mathrm{L})$

$\mathrm{C}_{\mathrm{e}}=$ Pollutant's aqueous phase concentration at equilibrium $(\mathrm{mg} / \mathrm{L})$

$\mathrm{M}=\mathrm{GAC}$ mass used $(\mathrm{g} / \mathrm{L})$

$\mathrm{q}_{\mathrm{e}}=[\mathrm{X} / \mathrm{M}]=($ Amount of pollutant adsorbed at equilibrium) / (GAC mass used)

$\mathrm{k}=$ Empirical constant

$\mathrm{n}=$ Slope inverse constant

A $1 \times 10^{-4} \mathrm{M}$ lead-EDTA adsorption kinetics study was also completed at GAC amount of $1 \mathrm{~g} / \mathrm{L}$. For the respective experiment, $1 \mathrm{~g}$ of GAC was added to $1 \mathrm{~L}$ 
batch of $1 \times 10^{-4} \mathrm{M}$ lead-EDTA synthetic wastewater along with vigorous mixing using a magnetic stirrer setup. Samples were then collected at several time intervals and the concentrations of both lead and EDTA were determined to realize the respective adsorption kinetic trend. The pH-dependent lead and EDTA adsorption isotherm studies were also conducted at 1 $\mathrm{g} / \mathrm{L} \mathrm{GAC}$ and aforementioned equilibrium time (use of respective GAC amount and time has been justified above). The respective EDTA-only adsorption studies were completed at $10^{-4} \mathrm{M}$ and $10^{-3} \mathrm{M}$ concentrations. The $\mathrm{pH}$ for these experiments was varied approximately between 2 and 9. Also the respective lead-EDTA adsorption studies were completed at the following varying ratios: $1 \times 10^{-4} \mathrm{M} \mathrm{Pb}$-EDTA, $2 \times 10^{-4} \mathrm{M} \mathrm{Pb}$ EDTA, $1 \times 10^{-3} \mathrm{M} \mathrm{Pb}$-EDTA, $1 \times 10^{-4} \mathrm{M} \mathrm{Pb}$ and $2 \times 10^{-4}$ MEDTA, $1 \times 10^{-4} \mathrm{M}$ Pb and $3 \times 10^{-4}$ MEDTA, $2 \times 10^{-4} \mathrm{M}$ $\mathrm{Pb}$ and $1 \times 10^{-4} \mathrm{M}$ EDTA, $3 \times 10^{-4} \mathrm{M} \mathrm{Pb}$ and $1 \times 10^{-4} \mathrm{M}$ EDTA. The $\mathrm{pH}$ for these experiments was varied approx. between 2 and 12. For each $\mathrm{pH}$-dependent adsorption experiment, a set of clean glass bottles with each bottle containing $100 \mathrm{~mL}$ of respective synthetic wastewater sample and GAC amount equivalent to $1 \mathrm{~g} / \mathrm{L}$, was first arranged. A blank sample (without $\mathrm{GAC}$ and $\mathrm{pH}$ adjustment) was also retrieved. The initial $\mathrm{pH}$ of each $100 \mathrm{~mL}$ sample was then adjusted to the desired value using an appropriate acid and/or base solution. The respective sample bottles were then appropriately sealed, transferred to a shaker and allowed to equilibrate as per the equilibrium adsorption isotherm study procedure that is mentioned above. Each sample was then tested for the final $\mathrm{pH}$ value and analyzed for lead and EDTA species. The continuous column adsorption saturation study was completed using a down flow setup with following conditions: $1 \times 10^{-4} \mathrm{M}$ lead, $0.75 \times$ $10^{-4}$ M EDTA, GAC amount $4 \mathrm{~g}$, GAC bed inner diameter $1 \mathrm{~cm}$, GAC bed length $7 \mathrm{~cm}$ and flow rate $3.4 \mathrm{~mL} / \mathrm{min}$.

The $\mathrm{pH}$ analyses were completed using a $\mathrm{pH}$ meter setup (ORION; U.S.A.) that was also regularly calibrated using the $\mathrm{pH}$ calibration standards. The aqueous EDTA concentration was indirectly monitored employing a standard TOC analyzer system (TOC-VCSN, SHIMADZU; Japan). The TOC system was calibrated employing the manufacturer-supplied standards. The lead species concentration was determined using a standard atomic absorption spectrophotometer setup (GBC; Australia) that was also regularly calibrated employing appropriate lead standards.

The lead and EDTA aqueous speciation was completed using MINTEQA2/PRODEFA2 software from U.S. EPA (Allison et al., 1991). Some important aqueous phase reactions used for the said speciation are provided in Table 1 and the respective details are given in Tables 2-5.

\section{RESULTS AND DISCUSSION}

First a $1 \times 10^{-4} \mathrm{M}$ lead-EDTA adsorption isotherm experiment was completed to estimate an appropriate GAC amount and equilibrium contact time that would be suitable for all $\mathrm{pH}$-dependent adsorption isotherm studies. As results from the respective adsorption isotherm experiment showed near-complete EDTA removal at $\mathrm{GAC}$ amount $\geq 2 \mathrm{~g} / \mathrm{L}$ at $3^{\text {rd }} \mathrm{day}$, a lower GAC amount i.e., $1 \mathrm{~g} / \mathrm{L}$ was subsequently used for all other experiments to avoid the masking effect resulting from high GAC amount and thus correctly quantifying the pollutant amount-adsorbed. The respective adsorption isotherm data for lead and EDTA was also fitted to the Freundlich and Langmuir isotherms. However the

Table 1: Reactions considered for lead and EDTA aqueous speciation $\left(\mathrm{T}=25^{\circ} \mathrm{C}\right)$

\begin{tabular}{|c|c|c|}
\hline No. & Reactions & $\log K$ \\
\hline 1 & $\mathrm{EDTA}^{4-}+5 \mathrm{H}^{+} \leftrightarrow \mathrm{H}_{5} \mathrm{EDTA}^{+}$ & 24.035 \\
\hline 2 & $\mathrm{EDTA}^{4-}+4 \mathrm{H}^{+} \leftrightarrow \mathrm{H}_{4} \mathrm{EDTA}$ & 22.499 \\
\hline 3 & $\mathrm{EDTA}^{4-}+3 \mathrm{H}^{+} \leftrightarrow \mathrm{H}_{3} \mathrm{EDTA}^{-}$ & 20.375 \\
\hline 4 & $\mathrm{EDTA}^{4-}+2 \mathrm{H}^{+} \leftrightarrow \mathrm{H}_{2} \mathrm{EDTA}^{2-}$ & 17.363 \\
\hline 5 & EDTA $^{4-}+\mathrm{H}^{+} \leftrightarrow \mathrm{HEDTA}^{3-}$ & 11.267 \\
\hline 6 & $\mathrm{~Pb}^{2+}+\mathrm{EDTA}^{4-} \leftrightarrow \mathrm{PbEDTA}^{2-}$ & 19.942 \\
\hline 7 & $\mathrm{~Pb}^{2+}+\mathrm{H}^{+}+\mathrm{EDTA}^{4-} \leftrightarrow \mathrm{PbHEDTA}^{-}$ & 23.035 \\
\hline 8 & $\mathrm{~Pb}^{2+}+2 \mathrm{H}^{+}+\mathrm{EDTA}^{4-} \leftrightarrow \mathrm{PbH}_{2}$ EDTA & 24.899 \\
\hline 9 & $\mathrm{~Pb}^{2+}+2 \mathrm{H}_{2} \mathrm{O} \leftrightarrow \mathrm{Pb}(\mathrm{OH})_{2 \mathrm{~s}}+2 \mathrm{H}^{+}$ & -8.150 \\
\hline 10 & $\mathrm{~Pb}^{2+}+\mathrm{H}_{2} \mathrm{O} \leftrightarrow \mathrm{PbOH}^{+}+\mathrm{H}^{+}$ & -7.562 \\
\hline 11 & $\mathrm{~Pb}^{2+}+2 \mathrm{H}_{2} \mathrm{O} \leftrightarrow \mathrm{Pb}(\mathrm{OH})_{2}+2 \mathrm{H}^{+}$ & -17.095 \\
\hline 12 & $\mathrm{~Pb}^{2+}+3 \mathrm{H}_{2} \mathrm{O} \leftrightarrow \mathrm{Pb}(\mathrm{OH})_{3}{ }^{-}+3 \mathrm{H}^{+}$ & -28.056 \\
\hline 13 & $2 \mathrm{~Pb}^{2+}+\mathrm{H}_{2} \mathrm{O} \leftrightarrow \mathrm{Pb}_{2}(\mathrm{OH})^{3+}+\mathrm{H}^{+}$ & -6.078 \\
\hline 14 & $3 \mathrm{~Pb}^{2+}+4 \mathrm{H}_{2} \mathrm{O} \leftrightarrow \mathrm{Pb}_{3}(\mathrm{OH})_{4}{ }^{2+}+4 \mathrm{H}^{+}$ & -23.746 \\
\hline 15 & $\mathrm{~Pb}^{2+}+4 \mathrm{H}_{2} \mathrm{O} \leftrightarrow \mathrm{Pb}(\mathrm{OH})_{4}{ }^{2-}+4 \mathrm{H}^{+}$ & -39.557 \\
\hline
\end{tabular}

Table 2: Aqueous speciation results for $10^{-4} \mathrm{M}$ EDTA

\begin{tabular}{cccccc}
\hline \multicolumn{1}{c}{ pH $^{3-}$} & 2 & 4 & 6 & 8 & 10 \\
\hline HEDTA $^{3-}$ & --- & --- & 37.0 & 98.2 & 88.0 \\
$\mathrm{H}_{2}$ EDTA $^{2-}$ & 3.3 & 88.3 & 62.9 & 1.60 & --- \\
$\mathrm{H}_{3}$ EDTA $^{-}$ & 34.6 & 11.0 & --- & --- & --- \\
$\mathrm{H}_{4}$ EDTA $^{+}$ & 46.2 & --- & --- & --- & --- \\
$\mathrm{H}_{5}$ EDTA $^{+}$ & 15.8 & --- & --- & --- & --- \\
EDTA $^{4-}$ & --- & --- & --- & --- & 12.0 \\
\hline
\end{tabular}

Table 3: Aqueous speciation results for $10^{-4} \mathrm{M}$ Pb-EDTA

\begin{tabular}{cccccc}
\hline $\mathrm{pH}$ & 2 & 4 & 6 & 8 & 10 \\
\hline $\mathrm{Pb}^{2+}$ & 6.7 & --- & --- & --- & --- \\
Pb-EDTAH $^{-}$ & 51.5 & 13.1 & --- & --- & --- \\
Pb-EDTAH $_{2}$ & 37.7 & --- & --- & --- & --- \\
Pb-EDTA $^{2-}$ & 4.1 & 86.8 & 99.8 & 100 & 100 \\
\hline
\end{tabular}


Freundlich isotherm fitted better to the experimental adsorption findings. Freundlich isotherm for lead adsorption is thus given as $\mathrm{q}_{\mathrm{e}}=[\mathrm{X} / \mathrm{M}]=\left[\mathrm{k}\left(\mathrm{C}_{\mathrm{e}}{ }^{1 / \mathrm{n}}\right)\right]=$ $3.0123 \mathrm{C}_{\mathrm{e}}^{1.1515}$ with $\mathrm{R}^{2}$ of 0.9926 . Abdulkarim and $\mathrm{Abu}$ Al-Rub, (2004) also reported that lead adsorption onto date-pits based activated carbon can be described by the Freundlich isotherm. Similarly the Freundlich adsorption isotherm for EDTA is given as $\mathrm{q}_{\mathrm{e}}=[\mathrm{X} / \mathrm{M}]=$ $\left[\mathrm{k}\left(\mathrm{C}_{\mathrm{e}}{ }^{1 / \mathrm{n}}\right)\right]=9.5501 \mathrm{C}_{\mathrm{e}}^{0.4163}$ with $\mathrm{R}^{2}$ of 0.9687. Furthermore, an adsorption kinetics study at $1 \times 10^{-4} \mathrm{M}$ lead-EDTA was also completed using GAC amount of $1 \mathrm{~g} / \mathrm{L}$. The respective results showed first order adsorption kinetics with $56 \%$ lead and $59 \%$ EDTA removal at time $140 \mathrm{~min}$; however Abdulkarim and Abu Al-Rub, (2004) reported a pseudo second order kinetics for lead adsorption onto date-pits based activated carbon that could result from differences in the pore structure of the two activated carbon samples. This in conjunction with the adsorption isotherm results also supported use of above mentioned GAC amount $(\mathrm{g} / \mathrm{L})$ and equilibrium time (days), for all $\mathrm{pH}$-dependent adsorption isotherm experiments, details of which are given below. Figs. 1 and 2 provide the lead and EDTA adsorption results, respectively, for several equimolar $\mathrm{Pb}$-EDTA systems. For the $1 \times 10^{-4} \mathrm{M} \mathrm{Pb}$-EDTA study an insignificant lead removal is noted at $\mathrm{pH} 2$, but with an increase in $\mathrm{pH}$ both lead and EDTA adsorptions increase reaching values of $\sim 82 \%$ and $\sim 93 \%$, respectively at $\mathrm{pH}$ 5.8. Similarly, Krishnan et al. (2003) also reported that lead adsorption in the presence of chelating agent was enhanced in $\mathrm{pH}$ range 2-5. However a further increase in $\mathrm{pH}$ results in decreasing but near equal lead and EDTA removals (Figs. 1 and 2, respectively). Krishnan et al. (2003) also reported that lead adsorption in the presence of chelating agent was reduced in $\mathrm{pH}$ range 6-8. Typically, the granular activated carbon surface is known to have several acidic functional groups including carboxylic, lactonic, hydroxyl, etc., which can be generalized by reaction 1 and reaction 2 as shown below (Barton et al., 1997; Corapcioglu and Huang, 1987, Chen and Wu, 2004):

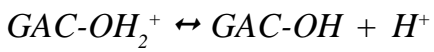

$\mathrm{GAC}-\mathrm{OH} \leftrightarrow \mathrm{GAC}-\mathrm{O}^{-}+\mathrm{H}^{+}$

Generally for lead-only systems a significant lead removal at higher $\mathrm{pH}$ will be expected because of a cationic type lead adsorption (i.e., GAC-O-Pb+) and also metal precipitation $\left(\mathrm{Pb}(\mathrm{OH})_{2 \mathrm{~s}}\right)$. Nevertheless, as indicated by the respective aqueous speciation results for equimolar $1 \times 10^{-4} \mathrm{M} \mathrm{Pb}$-EDTA system (Table 3 ) that at higher $\mathrm{pH}$ most lead will remain complexed to the EDTA species and therefore the above mentioned free metal removal phenomena (i.e., cationic-adsorption and precipitation) that are specific to free lead species will not transpire. This is why we do not observe significant lead removal at higher $\mathrm{pH}$ values for the $1 \times 10^{-4} \mathrm{M}$ lead-EDTA system. Rather an anionic type adsorption behavior (i.e., GAC-OH - EDTA-Pb-) is suggested to explain the decreasing and near equal lead and EDTA adsorption as noted at $\mathrm{pH}$ above 5.8 (Fig. 1). Faur-Brasquet et al. (2002) also suggested such a complex formation between the adsorbed benzoate and metals ions. Kadirvelu et al. (2000) who report copper, nickel and lead adsorption on to activated carbon cloths also suggested involvement of carboxylic groups at the surface of adsorbent. Hence

Table 4: Aqueous speciation results for Pb/EDTA systems (as \% of total Pb/EDTA; $\mathrm{Pb} 10^{-4} \mathrm{M}$, EDTA $3 \times 10^{-4} / 2 \times 10^{-4} \mathrm{M}$ )

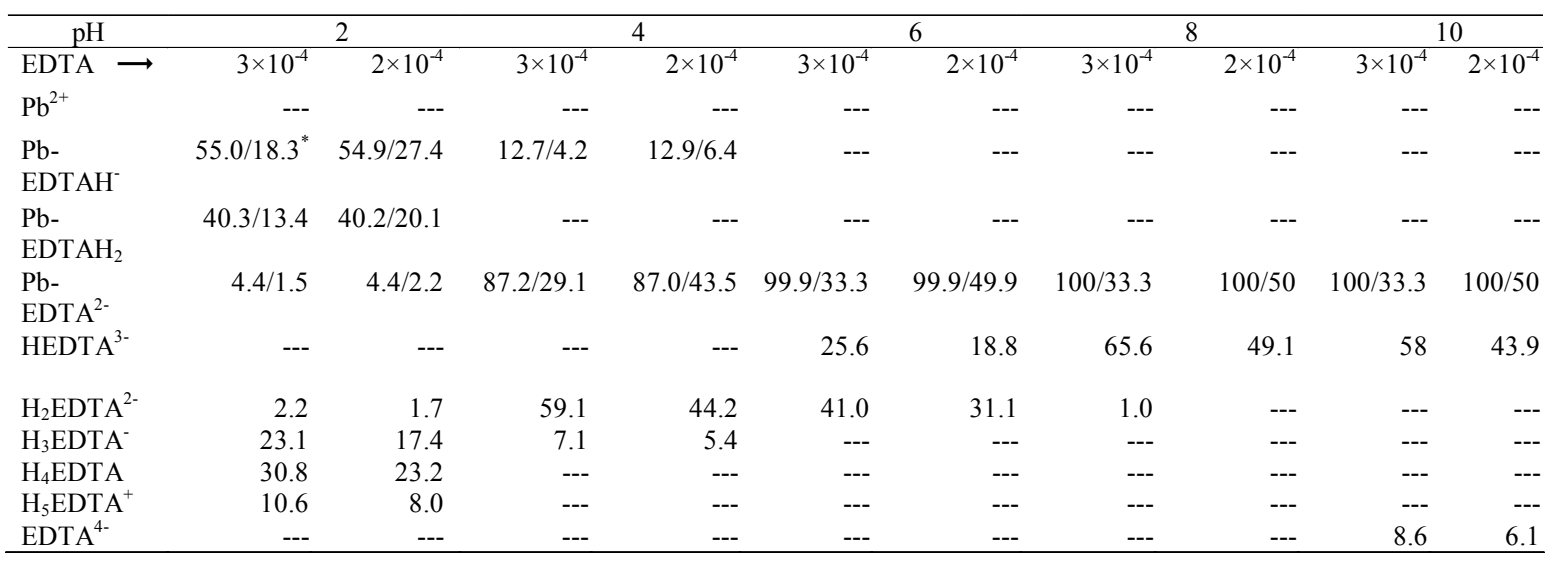

* \% of total $\mathrm{Pb}$ concentration / \% of total EDTA concentration 
as with an increase in $\mathrm{pH} 1$ ) the respective $\mathrm{GAC}$ cationic surface sites (i.e., GAC-OH${ }_{2}^{+}$) will decrease as indicated by reaction 1 and 2 ) the electrostatic conditions in the diffuse layer region of GAC particles will also become less conducive for the transport of dominant anionic

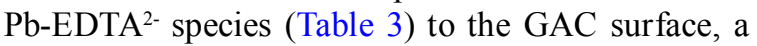
decrease in the respective anionic type adsorption would be expected (i.e., GAC-OH - -EDTA-Pb-) as noted in Fig. 1 and Fig. 2 as well. Reed and Arunachalam (1994) also found that the amount of aqueous phase lead that did not adsorb was comparable to its complexed form (i.e., lead-EDTA) whereas Reed et al. (1994) noted that metal complexed to EDTA was not adsorbed on to activated carbon from the aqueous waste streams. However as mentioned above the system $\mathrm{pH}$ seems to play a crucial role in this regard and hence should not be ignored.

To further clarify these trends, more equimolar leadEDTA adsorption experiments were conducted with pertinent lead and EDTA removal findings also summarized in Figs. 1 and 2, respectively. Results for the $2 \times 10^{-4} \mathrm{M}$ lead-EDTA system also show near equal lead and EDTA adsorption at $\mathrm{pH}$ above 4 , a behavior that is qualitatively similar to the $1 \times 10^{-4} \mathrm{M}$ lead-EDTA findings and can be explained employing the previously suggested anionic type adsorption mechanism. Though different from the above mentioned findings the $1 \times 10^{-3} \mathrm{M}$ lead-EDTA study shows only a decreasing type adsorption trend, however for all three equimolar lead-EDTA systems obvious close lead and EDTA adsorption values after a specific $\mathrm{pH}$ that varies with the lead-EDTA initial concentration. Additionally, for all these systems comparatively higher EDTA adsorption (than lead) transpires at $\mathrm{pH} \sim 2$ that indicates adsorption of both EDTA and lead-EDTA species. Abdulkarim and Abu Al-Rub, (2004) also reported significant decrease in lead uptake by activated carbon in the presence of EDTA.

Table 5: Aqueous speciation results for $\mathrm{Pb} / \mathrm{EDTA}$ systems (as \% of total $\mathrm{Pb} / \mathrm{EDTA}$; $\mathrm{Pb} 3 \times 10^{-4} / 2 \times 10^{-4} \mathrm{M}$, EDTA $1 \times 10^{-4} \mathrm{M}$ )

\begin{tabular}{|c|c|c|c|c|c|c|c|c|c|c|}
\hline $\mathrm{pH}$ & \multicolumn{2}{|c|}{2} & \multicolumn{2}{|c|}{4} & \multicolumn{2}{|c|}{6} & \multicolumn{2}{|c|}{7} & \multicolumn{2}{|c|}{8} \\
\hline $\mathrm{Pb} \longrightarrow$ & $3 \times 10^{-4}$ & $2 \times 10^{-4}$ & $3 \times 10^{-4}$ & $2 \times 10^{-4}$ & $3 \times 10^{-4}$ & $2 \times 10^{-4}$ & $3 \times 10^{-4}$ & $2 \times 10^{-4}$ & $3 \times 10^{-4}$ & $2 \times 10^{-4}$ \\
\hline $\mathrm{Pb}^{2+}$ & 66.7 & 50.2 & 66.7 & 50.2 & 52.2 & 48.8 & 0.51 & 0.9 & --- & --- \\
\hline $\begin{array}{l}\mathrm{Pb}- \\
\text { EDTAH }^{-}\end{array}$ & $18.4 / 55.1^{*}$ & $27.5 / 54.9$ & $4.2 / 12.7$ & $6.4 / 12.8$ & --- & --- & --- & --- & --- & --- \\
\hline $\begin{array}{l}\mathrm{Pb}- \\
\mathrm{EDTAH}_{2}\end{array}$ & $13.4 / 40.3$ & $20.1 / 40.2$ & --- & --- & --- & --- & --- & --- & --- & --- \\
\hline $\begin{array}{l}\text { Pb- } \\
\text { EDTA }^{2-}\end{array}$ & $1.5 / 4.4$ & $2.2 / 4.4$ & $29.1 / 87.2$ & $43.5 / 87.1$ & $\begin{array}{r}33.33 / \\
99.9\end{array}$ & $\begin{array}{r}49.9 / 9 \\
9.9\end{array}$ & $\begin{array}{r}33.33 / \\
100\end{array}$ & $50 / 100$ & $\begin{array}{r}33.4 / 10 \\
0\end{array}$ & $\begin{array}{r}50 / 10 \\
0\end{array}$ \\
\hline $\mathrm{PbOH}^{+}$ & -- & --- & --- & --- & 1.2 & 1.2 & --- & --- & --- & --- \\
\hline $\mathrm{Pb}(\mathrm{OH})_{2 \mathrm{~s}}$ & --- & --- & --- & --- & 13.2 & --- & 66.0 & 49.1 & 66.6 & 50 \\
\hline
\end{tabular}

* \% of total $\mathrm{Pb}$ concentration / \% of total EDTA concentration

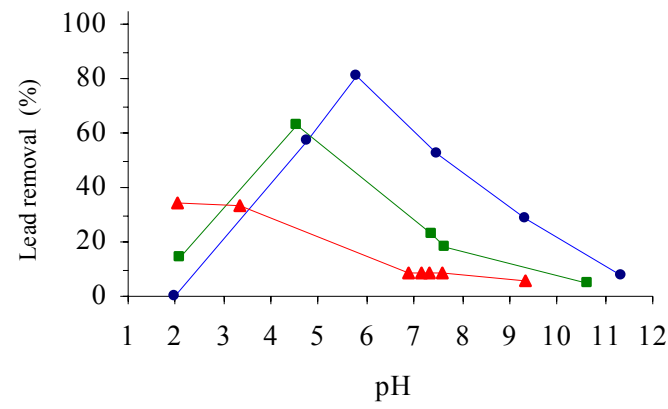

$\longrightarrow$ 1x10-4 M Pb-EDT A $\longrightarrow 2 \times 10-4$ M Pb-EDT

$\simeq 1 \times 10-3 \mathrm{M} \mathrm{Pb}-\mathrm{EDT} \mathrm{A}$

Fig. 1: Lead adsorption trends for the equimolar $\mathrm{Pb}$ EDTA systems $\left[1 \times 10^{-4} \mathrm{M}\right.$ Pb-EDTA, $2 \times 10^{-4} \mathrm{M} \mathrm{Pb}$ EDTA, $1 \times 10^{-3} \mathrm{M}$ Pb-EDTA; GAC amount $1 \mathrm{~g} / \mathrm{L}$; equilibrium time up to 3 days]

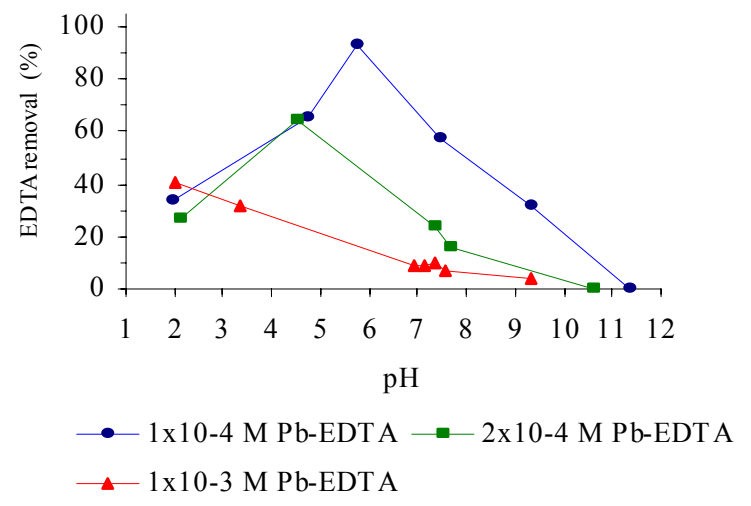

Fig. 2: EDTA adsorption trends for the equimolar Pb-EDTA systems $\left[1 \times 10^{-4} \mathrm{M}\right.$ Pb-EDTA, $2 \times 10^{-4} \mathrm{M}$ Pb-EDTA, $1 \times 10^{-3} \mathrm{M} \mathrm{Pb}$-EDTA; GAC amount $1 \mathrm{~g} / \mathrm{L}$; equilibrium time up to 3 days] 
Furthermore, Fig. 1 also indicates that lead removal at $\mathrm{pH} \sim 2$ tends to increase with an increase in the initial lead-EDTA concentration. In fact we note an increase both on percent-basis and mass-basis. Comparing the respective lead and EDTA adsorptions at $\mathrm{pH} \sim 2$ for all equimolar systems also shows that the gap between the respective lead and EDTA adsorption values widens with a decrease in the lead-EDTA concentration. This tends to indicate that the portion of lead-EDTA complex species adsorption is higher at higher initial lead-EDTA amount. Adsorption of lead on to activated carbons produced from coconut and seed hull of palm tree has been investigated and also indicated increased lead adsorption on to respective activated carbon samples with an increase in lead concentration (Gueu et al., 2007). To develop a better understanding of the above mentioned trends, some EDTA-only adsorption studies were conducted, as well. Fig. 3 provides the respective results. At $1 \times 10^{-4} \mathrm{M}$ EDTA, an increase followed by a decrease in EDTA adsorption with $\mathrm{pH}$ was noted. However, at $1 \times 10^{-3} \mathrm{M}$ EDTA, only an anionic type adsorption behavior transpires. Furthermore, though lower percent-based EDTA removal was observed at $1 \times 10^{-3} \mathrm{M}$ EDTA, however comparing the respective adsorption results on massbasis leaves a different impression, e.g., at $\mathrm{pH} \sim 2$, nearly $0.23 \times 10^{-3}$ and $0.035 \times 10^{-3} \mathrm{M}$ EDTA adsorptions transpire for the $1 \times 10^{-3}$ and $1 \times 10^{-4} \mathrm{M}$ EDTA systems, respectively. For the latter system though up to $0.05 \times 10^{-3} \mathrm{M}$ adsorption does result at a higher $\mathrm{pH}$ value (Fig. 3), nevertheless it is still smaller than the above mentioned maximum for the $1 \times 10^{-3} \mathrm{M}$ EDTA system. The aforementioned GAC surface speciation (reactions 1 and 2) in addition to EDTA speciation as provided in Table 2 can provide some insight into the adsorption behavior as noted in Fig. 3. Table 2 shows the following dominant EDTA-species regions: $\mathrm{H}_{4}$ EDTA and $\mathrm{H}_{3}$ EDTA $^{-}$species at $\mathrm{pH} 2, \mathrm{H}_{2}$ EDTA $^{2-}$ at $\mathrm{pH} 4$, $\mathrm{H}_{2}$ EDTA $^{2-}$ and HEDTA ${ }^{3-}$ at $\mathrm{pH} 6$ and HEDTA $^{3-}$ at $\mathrm{pH} 8$ and 10 . Hence as the solution $\mathrm{pH}$ goes up the EDTA species would start to shift from a neutral to increasingly negatively charged species. Though initially such a change favors increased EDTA adsorption because of an anionic EDTA species and cationic GAC surface, however with a further increase in $\mathrm{pH}$ that is followed by an increase in EDTA negative charge and also a gradual loss of positively charged GAC surface sites, we do note a decrease in the EDTA adsorption as well (Fig. 3). Now comparing the $10^{-3} \mathrm{M}$
EDTA-only (Fig. 3) and $10^{-3} \mathrm{M}$ lead-EDTA (Fig. 2) studies results, a significant increase is noted in EDTA removal at $\mathrm{pH} \sim 2$ in the presence of lead, i.e., $25 \% \mathrm{Vs}$ $41 \%$ respectively. Comparing the $10^{-4} \mathrm{M}$ EDTA-only and $10^{-4} \mathrm{M}$ lead-EDTA systems at $\mathrm{pH} 2$ however shows insignificant difference if any in the EDTA removal, thus indicating a similar surface bonding mechanism; nevertheless, comparing the respective EDTA removal results in the $\mathrm{pH} 6$ range, it is evident that higher EDTA adsorption transpires for the $1 \times 10^{-4} \mathrm{M}$ lead-EDTA system. Considering the EDTA-only and lead-EDTA aqueous speciation in the mentioned $\mathrm{pH}$ range (Tables 2 and 3, respectively), it can be suggested that a comparatively lower ionic charge on the Pb-EDTA ${ }^{2-}$ species compared to HEDTA ${ }^{3-}$ species will in turn require comparatively lesser amount of work to bring the former species close to the GAC surface, thus causing comparatively higher overall EDTA adsorption as noted in Fig. 2. The effect of EDTA concentration higher than lead on both lead and EDTA adsorption on to GAC was also investigated. Figs. 4 and 5 provide the respective details; results from the $1 \times 10^{-4} \mathrm{M}$ leadEDTA system are included in these Figs. for a comparison purpose. Similar to the equimolar leadEDTA studies, the EDTA adsorptions (for the EDTA > lead systems) at lower $\mathrm{pH}$ are also higher than the respective lead removals. This increase is both percent and mass based because of EDTA concentration being higher than lead. Nevertheless the respective lead removal results at lower $\mathrm{pH}$ also show an increase with an increase in EDTA concentration from $2 \times 10^{-4}$ to $3 \times$ $10^{-4} \mathrm{M}$, indicating that at higher EDTA amount the portion of lead-EDTA complex species adsorption is higher (Fig. 4). Amrate et al. (2006) who studied lead removal using integrated cation-exchange membrane with electrokinetic extraction also report enhanced removal of lead in the presence of EDTA. Similarly, Chen and Wang (2000) also report increased copper and zinc removal by activated carbon upon the addition of EDTA to the influent. Faur-Brasquet et al. (2002) who report copper and lead adsorption on to activated carbon cloths also indicate increased metal ion removal in the presence of benzoic acid because of a complex formation between the adsorbed benzoate and metals ions. Aroua et al. (2009) who studied the effect of polyethyleneimine (chelating polymer) impregnation of plam shell activated carbon on to lead adsorption also report higher metal uptake at higher chelating polymer concentration. Furthermore Zhu et 


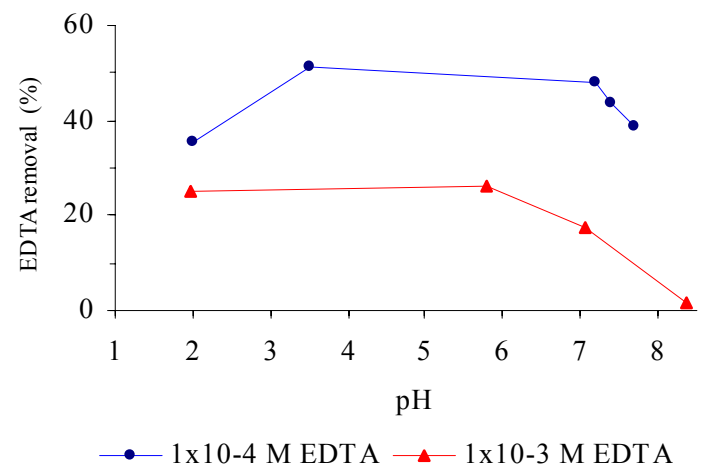

Fig. 3: Adsorption trends for EDTA-only systems $\left[1 \times 10^{4} \mathrm{M}\right.$ EDTA, $1 \times 10^{-3} \mathrm{M}$ EDTA; GAC amount $1 \mathrm{~g} / \mathrm{L}$; equilibrium time up to 3 days]

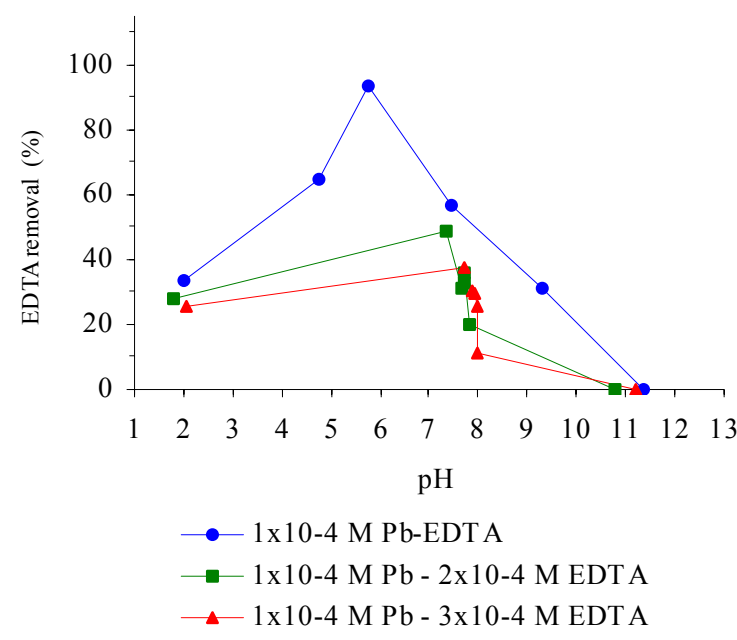

Fig. 5: EDTA adsorption trends for EDTA $>\mathrm{Pb}$ systems $[1 \times 10$ ${ }^{4} \mathrm{M} \mathrm{Pb}$-EDTA, $1 \times 10^{-4} \mathrm{M} \mathrm{Pb}$ and $2 \times 10^{-4} \mathrm{M}$ EDTA, $1 \times 10^{-4} \mathrm{M} \mathrm{Pb}$ and $3 \times 10^{-4} \mathrm{M}$ EDTA; GAC amount $1 \mathrm{~g} / \mathrm{L}$; equilibrium time up to 3 days]

al. (2009) also report that lead uptake by ethylenediamine modified activated carbon was comparatively faster with $62 \%$ higher capacity as compared to the unmodified activated carbon. Sreejalekshmi et al. (2009) also reported higher lead uptake by sawdust activated carbon in the presence of citric acid. Additionally, comparing the respective EDTA removal results at lower $\mathrm{pH}$ shows that higher mass based removals result for the higher EDTA concentration system (Fig. 5). For the $1 \times 10^{-4} \mathrm{M}$ lead $/ 2$ $\times 10^{-4}$ M EDTA system, in addition to the above mentioned higher EDTA adsorption than lead at lower $\mathrm{pH}$, an increasing-decreasing type lead and EDTA adsorption behavior was also noted. Both of these

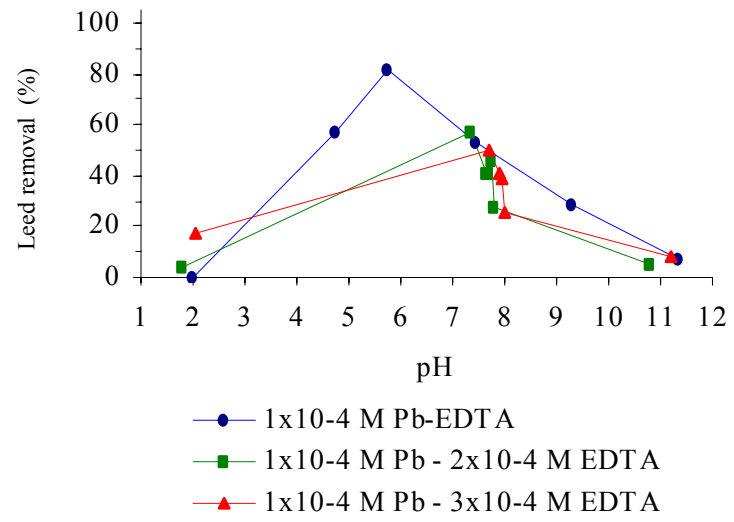

Fig. 4: Lead adsorption trends for EDTA $>\mathrm{Pb}$ systems $\left[1 \times 10^{-}\right.$ ${ }^{4} \mathrm{M} \mathrm{Pb}$-EDTA, $1 \times 10^{-4} \mathrm{M} \mathrm{Pb}$ and $2 \times 10^{-4} \mathrm{M}$ EDTA, $1 \times 10^{-4} \mathrm{M} \mathrm{Pb}$ and $3 \times 10^{-4} \mathrm{M}$ EDTA; GAC amount $1 \mathrm{~g} / \mathrm{L}$; equilibrium time up to 3 days]

observations resemble to the previously mentioned equimolar $10^{-4} \mathrm{M}$ lead-EDTA adsorption findings. However, a sudden drop in both lead and EDTA adsorption as noted in $\mathrm{pH}$ range $7 \sim 8$ and shown in Figs. 4 and 5, respectively for $1 \times 10^{-4} \mathrm{M}$ lead $/ 2 \times 10^{-4} \mathrm{M}$ EDTA system, is different from the $10^{-4} \mathrm{M}$ lead-EDTA study. A similar cliff-type adsorption trend in $\mathrm{pH}$ range $7 \sim 8$ is noted for $1 \times 10^{-4} \mathrm{M}$ lead $/ 3 \times 10^{-4} \mathrm{M}$ EDTA system as well (Figs. 4 and 5). Though a competitive adsorption between the EDTA species and lead-EDTA complex (with EDTA > lead) may partially explain the noted trend however the question that remains is why both species show a similar trend? Table 4 that provides the respective aqueous speciation trends shows that between $\mathrm{pH} 6$ and 8 a significant portion of uncomplexed-EDTA converts from $\mathrm{H}_{2}$ EDTA $^{2-}$ to HEDTA $^{3-}$ species. However this change in EDTA speciation would only explain the aforementioned clifftype trend for EDTA but not for lead as any significant change is not seen in the lead speciation between $\mathrm{pH}$ 6 and 8 . Nevertheless, for the respective EDTA $>$ lead systems a sizable lead and EDTA adsorption can still be achieved via a careful control of $\mathrm{pH}$.

Adsorption experiments at lead concentration higher than EDTA were also conducted with Figs. 6 and 7 providing the respective findings; results from the $1 \times 10^{-4} \mathrm{M}$ lead-EDTA system are included in these Figs. for a comparison purpose. Comparing the EDTA removal results from Figs. 3 and 7 shows that generally the EDTA adsorption is higher for the latter system. It should also be noted that for the $2 \times 10^{-4} \mathrm{M}$ lead $/ 1 \times 10^{-}$ 
${ }^{4}$ M EDTA system at $\mathrm{pH} \sim 2$ insignificant lead but significant EDTA adsorption is noted. This trend is very similar to respective $1 \times 10^{-4} \mathrm{M}$ lead-EDTA and $1 \times 10^{-4} \mathrm{lead} / 2 \times 10^{-4}$ $M$ EDTA trends. With an increase in lead to $3 \times 10^{-4} \mathrm{M}$ while keeping EDTA at $1 \times 10^{-4} \mathrm{M}$, an insignificant lead removal was again noted at $\mathrm{pH} \sim 2$ (Fig. 6). Comparing this to the $1 \times 10^{-4} \mathrm{M}$ lead $/ 3 \times 10^{-4} \mathrm{M}$ EDTA findings (Fig. 4) it can be concluded that having EDTA higher than lead certainly increases latter's removal but vice versa does not yield a similar outcome. On the $2 \times 10^{-4} \mathrm{M}$ lead $/ 1 \times 10^{-}$ ${ }^{4} \mathrm{M}$ EDTA system, though an increasing-decreasing type adsorption trend is noted for the EDTA species (that is qualitatively similar to the previously mentioned equimolar lead-EDTA and EDTA > lead systems findings) however the overall decrease in lead removal at increased $\mathrm{pH}$ is not as significant compared to the other two lead/EDTA systems (Figs. 1 and 4). The most obvious reasoning is that though a small decrease in lead concentration does result at higher $\mathrm{pH}$ because of reduced lead-EDTA adsorption, but still the remaining free metal species (i.e., 1 $\times 10^{-4} \mathrm{M}$ lead) will be partially removed both because of 1 ) precipitation $\left(\mathrm{Pb}(\mathrm{OH})_{2 \mathrm{~s}}\right)$ and 2$)$ adsorption $\left(\mathrm{GAC}-\mathrm{O}-\mathrm{Pb}^{+}\right)$. Abdel-Ghani et al. (2007) also report increased lead adsorption on to some low cost adsorbents, with an increase in $\mathrm{pH}$. For example, for the $1 \times 10^{-4} \mathrm{M}$ lead-EDTA system at $\mathrm{pH} 7.5$ approximately $53 \%$ lead removal is noted that is equal to $5.3 \times 10^{-5} \mathrm{M}$, whereas for the $2 \times 10^{-4} \mathrm{M}$ lead $/ 1 \times 10^{-4} \mathrm{M}$ EDTA system we note $60 \%$ lead removal that is equal to $1.2 \times 10^{-4} \mathrm{M}$. Hence nearly $0.67 \times 10^{-4} \mathrm{M}$ additional lead removal that transpires for the latter system can partially be explained because of precipitation. Table 5

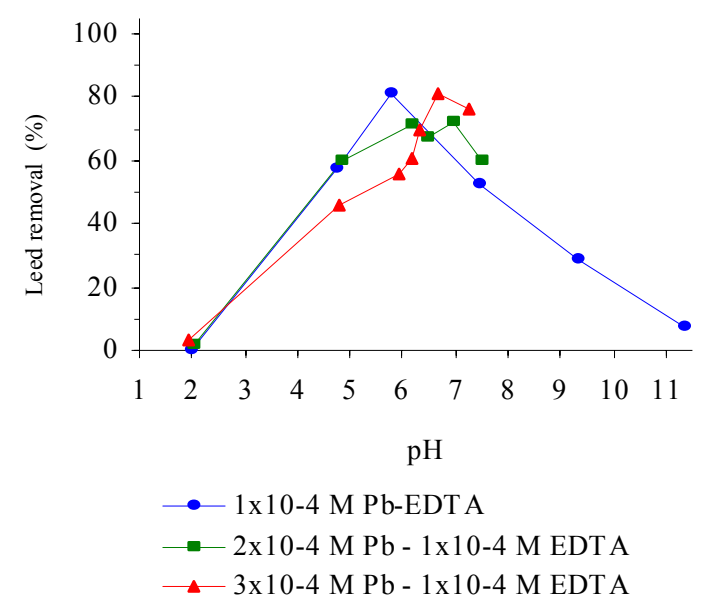

Fig. 6: Lead adsorption trends for $\mathrm{Pb}>$ EDTA systems $[1 \times$ $10^{-4} \mathrm{M} \mathrm{Pb}$-EDTA, $2 \times 10^{-4} \mathrm{M} \mathrm{Pb}$ and $1 \times 10^{-4} \mathrm{M}$ EDTA, $3 \times 10^{-4} \mathrm{M} \mathrm{Pb}$ and $1 \times 10^{-4} \mathrm{M}$ EDTA; GAC amount $1 \mathrm{~g} / \mathrm{L}$; equilibrium time up to 3 days] that provides the aqueous speciation trends for the lead $>$ EDTA systems also shows nearly $50 \%\left(1 \times 10^{-4} \mathrm{M}\right)$ lead precipitation for the $2 \times 10^{-4} \mathrm{M}$ lead $/ 1 \times 10^{-4} \mathrm{MEDTA}$ system between $\mathrm{pH}$ 7-8. Overall, significant lead and EDTA removal can be achieved for the lead $>$ EDTA systems as indicated by trends in Figs. 6 and 7 .

Eventually a continuous column adsorption saturation study was also completed at $1 \times 10^{-4} \mathrm{M}$ lead and $0.75 \times$ $10^{-4} \mathrm{M}$ EDTA. The respective results as provided in Fig. 8 show high saturation times both for lead and EDTA. Hence placement of sufficient carbon adsorption columns in series would maximize the usage of

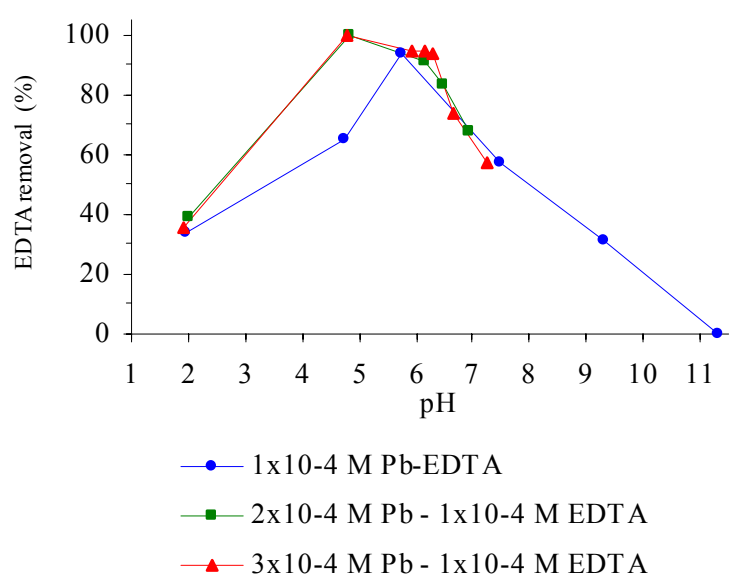

Fig. 7. EDTA adsorption trends for $\mathrm{Pb}$ eH EDTA systems $[1 \times$ $10^{-4} \mathrm{M} \mathrm{Pb}$-EDTA, $2 \times 10^{-4} \mathrm{M} \mathrm{Pb}$ and $1 \times 10^{-4} \mathrm{M}$ EDTA, $3 \times 10^{-4} \mathrm{M} \mathrm{Pb}$ and $1 \times 10^{-4} \mathrm{M}$ EDTA; GAC amount $1 \mathrm{~g} / \mathrm{L}$; equilibrium time up to 3 days]

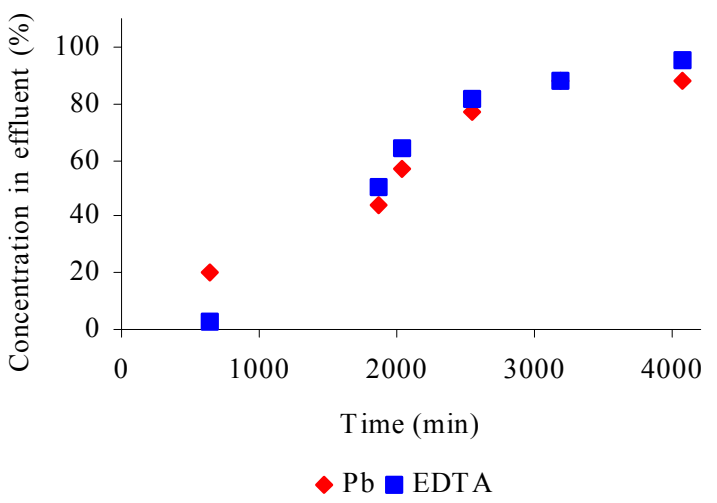

Fig. 8: Lead and EDTA adsorption trends from a continuous column adsorption saturation study $\left[1 \times 10^{-4} \mathrm{M}\right.$ lead and $0.75 \times 10^{-4} \mathrm{M}$ EDTA; GAC amount $4 \mathrm{~g}$; GAC bed inner diameter $1 \mathrm{~cm}$; GAC bed length $7 \mathrm{~cm}$; Flow rate $3.4 \mathrm{~mL} / \mathrm{min}$ ] 
respective GAC (in terms of pollutant removed from the aqueous phase per unit weight of GAC) while meeting effluent requirements for lead and EDTA.

\section{CONCLUSION}

The present study investigated simultaneous adsorption of lead and EDTA onto granular activated carbon under varying conditions. Data from a $1 \times 10^{-4} \mathrm{M}$ lead-EDTA adsorption isotherm study was noted to fit well to Freundlich adsorption isotherm both for lead and EDTA. The Freundlich adsorption isotherm for lead was noted to be $\mathrm{q}_{\mathrm{e}}=[\mathrm{X} / \mathrm{M}]=\left[\mathrm{k}\left(\mathrm{C}_{\mathrm{e}}{ }^{1 / \mathrm{n}}\right)\right]=3.0123 \mathrm{C}_{\mathrm{e}}{ }^{1.1515}$ with $\mathrm{R}^{2}$ of 0.9926 . Similarly, the Freundlich adsorption isotherm for EDTA was noted to be $\mathrm{q}_{\mathrm{e}}=[\mathrm{X} / \mathrm{M}]=[\mathrm{k}$ $\left.\left(\mathrm{C}_{\mathrm{e}}{ }^{1 \mathrm{n}}\right)\right]=9.5501 \mathrm{C}_{\mathrm{e}}^{0.4163}$ with $\mathrm{R}^{2}$ of 0.9687. Furthermore an adsorption kinetics study at $1 \times 10^{-4} \mathrm{M}$ lead-EDTA and GAC amount of $1 \mathrm{~g} / \mathrm{L}$ showed first order adsorption kinetics with $56 \%$ lead and $59 \%$ EDTA removal at time $140 \mathrm{~min}$. For equimolar $1 \times 10^{-4} \mathrm{M}$ lead-EDTA pHdependent adsorption study approximately $82 \%$ and 93 $\%$ lead and EDTA adsorptions respectively were noted at $\mathrm{pH}$ 5.8. However, a further increase in $\mathrm{pH}$ resulted in decreasing but near equal lead and EDTA removals. Results for the $2 \times 10^{-4} \mathrm{M}$ lead-EDTA system showed a qualitatively similar behavior whereas the $1 \times 10^{-3} \mathrm{M}$ lead-EDTA study showed only a decreasing type adsorption trend with $\mathrm{pH}$. Comparing the $10^{-3} \mathrm{M}$ EDTA-only and $10^{-3} \mathrm{M}$ lead-EDTA studies showed a significant increase in EDTA removal at $\mathrm{pH} \sim 2$ in the presence of lead. An increasing-decreasing type lead/ EDTA adsorption behavior was also noted for the $1 \times 10^{-4} \mathrm{M}$ lead $/ 2 \times 10^{-4} \mathrm{M}$ EDTA and $1 \times 10^{-4} \mathrm{M}$ lead $/ 3 \times$ $10^{-4} \mathrm{M}$ EDTA systems. For the $2 \times 10^{-4} \mathrm{M}$ lead $/ 1 \times$ $10^{-4} \mathrm{M}$ EDTA system, though an increasing-decreasing type adsorption trend was noted for the EDTA species however the overall decrease in lead removal at increased $\mathrm{pH}$ was not as significant as compared to the other two lead/EDTA systems. In general, a sizable lead and EDTA removal was achieved for all studied lead-EDTA $\mathrm{pH}$ dependent adsorption isotherm studies. Furthermore, a continuous column adsorption saturation study was also completed at $1 \times 10^{-4} \mathrm{M}$ lead and $0.75 \times 10^{-4} \mathrm{M}$ EDTA. The respective results showed high saturation times both for lead and EDTA indicating that placement of carbon adsorption columns in series would maximize the usage of respective GAC while meeting effluent requirements for lead and EDTA.

\section{ACKNOWLEDGEMENTS}

The author would like to thank the King Fahd
University of Petroleum and Minerals (KFUPM) for providing the necessary support for this study.

\section{REFRENCES}

Abdel-Ghani, N. T.; Elchaghaby, G. A., (2007). Influence of operating conditions on the removal of $\mathrm{Cu}, \mathrm{Zn}, \mathrm{Cd}$ and $\mathrm{Pb}$ ions from wastewater by adsorption. Int. J. Environ. Sci. Tech., 4 (4), 451-456 (6 pages).

Abdel-Ghani, N. T.; Hegazy, A. K.; El-Chaghaby, G. A., (2009). Typha domingensis leaf powder for decontamination of aluminium, iron, zinc and lead: Biosorption kinetics and equilibrium modeling. Int. J. Environ. Sci. Tech., 6 (2), 243248 (6 pages).

Abdulkarim, M.; Abu Al-Rub, F., (2004). Adsorption of lead ions from aqueous solution onto activated carbon and chemicallymodified activated carbon prepared from date pits. Adsorp. Sci. Tech., 22 (2), 119-134 (15 pages).

Aghamohammadi, N.; Hamidi, A. A.; Hasnain, I. M.; Zinatizadeh, A. A.; Nasrollahzadeh Saravi, H.; Ghafari, Sh., (2007). Performance of a powdered activated carbon (PAC) augmented activated sludge process treating semi-aerobic leachate. Int. J. Environ. Res., 1 (2), 96-103 (8 pages).

Allison, J. D.; Brown, D. S.; Novo-Gradac, K. J., (1991). MINTEQA2/PRODEFA2, A Geochemical Assessment Model for Environmental Systems, Version 3.0 User's Manual, U.S. Environmental Protection Agency, EPA/600/3-91/021, Athens, Georgia.

Amrate, S.; Akretche, D. E.; Innocent, C.; Seta, P., (2006). Use of cation-exchange membranes for simultaneous recovery of lead and EDTA during electrokinetic extraction. Desalination, 193 (1-3), 405-410 (6 pages).

Aroua, M. K.; Yin, C. Y.; Lim, F. N.; Kan, W. L.; Daud, W. M. A. W., (2009). Effect of impregnation of activated carbon with chelating polymer on adsorption kinetics of $\mathrm{Pb}^{2+}$. J. Hazard. Mater., 166 (2-3), 1526-1529 (4 pages).

Awwad, N. S.; Daifuallah, A. A. M.; Ali, M. M. S., (2008). Removal of $\mathrm{Pb}^{2+}, \mathrm{Cd}^{2+}, \mathrm{Fe}^{3+}$, and $\mathrm{Sr}^{2+}$ from aqueous solution by selected activated carbons derived from date pits. Solvent Extr. Ion Exc., 26 (6), 764-782 (19 pages).

Bargar, J. R.; Persson, P.; Brown Jr., G. E., (1999). Outer-sphere adsorption of $\mathrm{Pb}$ (II)EDTA on goethite. Geochim. Cosmochim. Ac., 63 (19-20), 2957-2969 (13 pages).

Barton, S. S.; Evans, M. J. B.; Halliop, E.; MacDonald, J. A. F., (1997). Acidic and basic sites on the surface of porous carbon. Carbon, 35 (9), 1361-1366 (6 pages).

Chen, J. P.; Wang, X., (2000). Removing copper, zinc, and lead ion by granular activated carbon in pretreated fixed-bed columns. Separ. Purif. Tech., 19 (3), 157-167 (11 pages).

Chen, J. P.; Wu, S., (2004). Simultaneous adsorption of copper ions and humic acid onto an activated carbon. J. Coll. Inter.Sci., 280 (2), 334-342 (9 pages).

Corapcioglu, M. O.; Huang, C. P., (1987). The surface acidity and characterization of some commercial activated carbons. Carbon, 25 (4), 569-578 (10 pages).

Dudzinska, M. R.; Clifford, D. A., (1992). Anion exchange studies of lead-EDTA complexes. React.Polymer., 16 (1), 71-80 (10 pages).

Faur-Brasquet, C.; Kadirvelu, K.; Le Cloirec, P., (2002). Removal of metal ions from aqueous solution by adsorption onto activated carbon cloths: Adsorption competition with organic matter. Carbon, 40 (13), 2387-2392 (6 pages). 
Gaur, N.; Dhankhar, R., (2009). Removal of $\mathrm{Zn}^{+2}$ ions from aqueous solution using Anabaena variabilis: Equilibrium and kinetic studies. Int. J. Environ. Res., 3 (4), 605-616 (12 pages).

Giraldo, L.; Moreno-Piraján, J. C., (2008). $\mathrm{Pb}^{2+}$ adsorption from aqueous solutions on activated carbons obtained from lignocellulosic residues. Brazil. J. Chem. Eng., 25 (1), 143151 (9 pages).

Goel, J.; Kadirvelu, K.; Rajagopal, C.; Garg, V. K., (2005). Investigation of adsorption of lead, mercury and nickel from aqueous solutions onto carbon aerogel. Journal of Chemical Technology and Biotechnology, 80 (4), 469-476 (8 pages).

Gueu, S.; Yao, B.; Adouby, K.; Ado, G., (2007). Kinetics and thermodynamics study of lead adsorption on to activated carbons from coconut and seed hull of the palm tree. Int. J. Environ. Sci. Tech., 4 (1), 11-17 (7 pages).

Igbinosa, E. O.; Okoh, A. I., (2009). Impact of discharge wastewater effluents on the physico-chemical qualities of a receiving watershed in a typical rural community. Int. J. Environ. Sci. Tech., 6 (2), 175-182 (8 pages).

Issabayeva, G.; Aroua, M. K.; Sulaiman, N. M. N., (2006). Removal of lead from aqueous solutions on palm shell activated carbon. Bioresour. Tech., 97 (18), 2350-2355 (6 pages).

Jiraroj, D.; Unob, F.; Hagège, A., (2006). Degradation of PbEDTA complex by a $\mathrm{H}_{2} \mathrm{O}_{2} / \mathrm{UV}$ process. Water Res., 40 (1), 107-112 (6 pages).

Juang, R. S.; Wang, S. W.; Lin, L. C., (1999). Simultaneous recovery of EDTA and lead(II) from their chelated solutions using a cation exchange membrane. J. Membr. Sci., 160 (2), 225-233 (9 pages).

Kadirvelu, K.; Faur-Brasquet, C.; Le Cloirec, P., (2000). Removal of $\mathrm{Cu}(\mathrm{II}), \mathrm{Pb}(\mathrm{II})$, and $\mathrm{Ni}(\mathrm{II})$ by adsorption onto activated carbon cloths. Langmuir, 16 (22), 8404-8409 (6 pages).

Kim, C.; Ong, S. K., (1999). Recycling of lead-contaminated EDTA wastewater. J. Hazard. Mater., 69 (3), 273-286 (14 pages)

Kołodyńska, D.; Skwarek, E.; Hubicki, Z.; Janusz, W., (2009). Effect of adsorption of $\mathrm{Pb}(\mathrm{II})$ and $\mathrm{Cd}(\mathrm{II})$ ions in the presence of EDTA on the characteristics of electrical double layers at the ion exchanger/ $\mathrm{NaCl}$ electrolyte solution interface. J. Coll. Inter. Sci., 333 (2), 448-456 (9 pages).

Krishnan, K. A.; Sheela, A.; Anirudhan, T., (2003). Adsorption of lead and lead chelates on activated carbons. J. Chem. Tech. Biotech., 78 (6), 642-653 (12 pages)

Li, Y.-H.; Di, Z.; Ding, J.; Wu, D.; Luan, Z.; Zhu, Y., (2005). Adsorption thermodynamic, kinetic and desorption studies of $\mathrm{Pb}^{2+}$ on carbon nanotubes. Water Res., 39 (4), 605-609 (5 pages).

Malakootian, M.; Nouri, J.; Hossaini, H., (2009). Removal of heavy metals from paint industries wastewater using Leca as an available adsorbent. Int. J. Environ. Sci. Tech., 6 (2), 183190 (7 pages).
Oviedo, C.; Rodríguez, J., (2003). EDTA: The chelating agent under environmental scrutiny. Quim. Nova, 26 (6), 901-905 (5 pages).

Palacios, H.; Iribarren, I.; Olalla, M. J.; Cala, V., (2002). Lead poisoning of horses in the vicinity of a battery recycling plant. Sci. Total Environ., 290 (1-3), 81-89 (9 pages).

Reed, B. E.; Arunachalam, S., (1994). Use of granular activated carbon for lead removal. J.Environ. Eng., 120 (2), 416-436 (21 pages).

Reed, B. E.; Arunachalam, S.; Thomas, B., (1994). Removal of lead and cadmium from aqueous waste streams using granular activated carbon (GAC) columns. Environ. Prog., 13 (1), 6064 (5 pages).

Riley, R. G.; Zachara, J. M.; Wobber, F. J., (1992). Chemical contaminants on DOE lands and selection of contaminated mixtures for subsurface science research, U.S. Department of Energy, DOE/ER-0547T.

Shah, B. A.; Shah, A. V.; Singh R. R., (2009). Sorption isotherms and kinetics of chromium uptake from wastewater using natural sorbent material. Int. J. Environ. Sci. Tech., 6 (1), 77-90 (14 pages)

Sreejalekshmi, K. G.; Anoop Krishnan, K.; Anirudhan, T. S., (2009). Adsorption of $\mathrm{Pb}(\mathrm{II})$ and $\mathrm{Pb}$ (II)-citric acid on sawdust activated carbon: Kinetic and equilibrium isotherm studies. J. Hazard. Mater., 161 (2-3), 1506-1513 (8 pages).

Swanson, J. L., (1984). Organic complexant-enhanced mobility of toxic elements in low-level wastes, Pacific Northwest Lab., PNL-SA-12518, Washington.

Swanson, J. L., (1985). Organic complexant-enhanced mobility of toxic elements in low-level wastes, Pacific Northwest Lab., PNL-4965-8, Washington.

Taylor, R. M.; Kuennen, R. W., (1994). Removing lead in drinking water with activated carbon. Environ. Prog., 13 (1), 65-71 (7 pages).

Vohra, M. S.; Davis, A. P., (1998). Adsorption of Pb(II), EDTA, and $\mathrm{Pb}(\mathrm{II})$-EDTA onto $\mathrm{TiO}_{2}$. J. Coll. Inter.e Sci., 198, 18-26 (9 pages).

Vohra, M. S.; Davis, A. P., (2000). $\mathrm{TiO}_{2}$-assisted photocatalysis of lead-EDTA. Water Res., 34 (3), 952-964 (13 pages).

Xia, W.; Gao, H.; Wang, X.; Zhou, C.; Liu, Y.; Fan, T.; Wang, X., (2009). Application of EDTA decontamination on soils affected by mining activities and impact of treatment on the geochemical partition of metal contaminants. J. Hazard. Mater., 164 (2-3), 936-940 (5 pages).

Zhang, K.; Cheung, W. H.; Valix, M., (2005). Roles of physical and chemical properties of activated carbon in the adsorption of lead ions. Chemosphere, 60 (8), 1129-1140 (12 pages).

Zhu, J.; Yang, J.; Deng, B., (2009). Ethylenediamine-modified activated carbon for aqueous lead adsorption. Environ. Chem. Lett., 12 (2), 113-117 (5 pages).

Zvinowanda, C. M.; Okonkwo, J. O.; Shabalala, P. N.; Agyei, N.M., (2009). A novel ad'sorbent for heavy metal remediation in aqueous environments. Int. J. Environ. Sci. Tech. 6 (3), 425-434 (10 pages).

\section{AUTHOR (S) BIOSKETCHES}

Vohra, M. S., Ph.D., Assistant Professor, Environmental Engineering Program, Civil Engineering Department, King Fahd University of Petroleum and Minerals, Dhahran 31261, Kingdom of Saudi Arabia. Email: vohra@kfupm.edu.sa

Vohra, M. S., (2010). Adsorption of lead, ethylenediaminetetraacetic acid and lead-ethylenediaminetetraacetic acid complex on to granular activated carbon. Int. J. Environ. Sci. Tech., 7 (4), 687-696. 